\title{
Relationship between the Berg Balance Scale and Static Balance Test in Hemiplegic Patients with Stroke
}

\author{
Makoto Suzuki, RPT, $\mathrm{PhD}^{1)^{*}}$, Hiroyuki Fujisawa, RPT, $\mathrm{PhD}^{2)}$, Yooichiro Machida, RPT ${ }^{3)}$, \\ Shin Minakata, RPT, MSc ${ }^{3)}$ \\ 1) Department of Rehabilitation, Faculty of Medical Science and Welfare, Tohoku Bunka Gakuen \\ University: 6-45-1 Kunimi, Aoba-ku, Sendai, Miyagi 981-8551, Japan. TEL: +81 22-233-3854, \\ FAX: +81 22-233-3854 \\ 2) Graduate School of Health and Environment Sciences, Tohoku Bunka Gakuen University \\ 3) Department of Strokology and Rehabilitation, Research Institute for Brain and Blood Vessels, AKITA
}

\begin{abstract}
Purpose] The purpose of this study was to analyze the relationship between results of the Berg Balance Scale (BBS) and Static Balance Test (SBT) in hemiplegic patients with stroke. [Subjects] The subjects were 39 hemiplegic patients ( 25 men, 14 women; mean age, $69.4 \pm 11.0$ years) with stroke that had occurred within the preceding 6 months and who had good understanding of verbal instructions. [Methods] The SBT consists of five posture-holding tasks (sitting, stride standing, close standing, one-foot standing on the unparalyzed leg, and onefoot standing on the paralyzed leg). Four grades, 1-4, are used to judge the ability of patients to hold these postures. The SBT and BBS were each implemented, and the relationship between test results was analyzed using correlation coefficients. [Results] The correlation coefficient for the BBS score and SBT score was 0.87 . Thus, a strong correlation was seen between the BBS and SBT. [Conclusion] The SBT is thought to be an assessment index that can predict overall balance ability.

Key words: Stroke, Balance, Assessment
\end{abstract}

(This article was submitted Mar. 12, 2013, and was accepted Apr. 10, 2013)

\section{INTRODUCTION}

Many hemiplegic patients with stroke shift their center of gravity (COG) to the unaffected side when maintaining a quiet stance and show left-right asymmetry in motor function; a fair number also show decreased balance ability ${ }^{1)}$. These factors likely lead to decreased activities of daily living (ADLs) and quality of life. Assessment of balance ability in hemiplegic patients with stroke is therefore important when interpreting their disabilities and investigating methods of intervention. However, most tests of static balance used in clinical settings in hemiplegic patients with stroke judge whether the individual can maintain a posture for a certain time, without sufficient consideration of their conditions. In other words, existing assessment methods are inadequate for detailed analyses of static balance problems in hemiplegic patients with stroke. We developed the Static Balance Test (SBT), which consists of five posture-holding tasks. This balance assessment method expands the measurement range by changing the position at which the COG is held within the same base of support, making more detailed judgments possible. The validity and reliability ${ }^{2)}$ of the SBT as an evaluation battery and its relationship with balance performance ${ }^{3)}$ have been reported. However, al-

\footnotetext{
*To whom correspondence should be addressed

E-mail:m-suzuki@rehab.tbgu.ac.jp
}

though the utility of the SBT has been shown, its correlation with the Berg Balance Scale (BBS), which is widely used in clinical settings, has not been adequately investigated. The BBS is an index developed by Berg and colleagues to assess overall balance ability in elderly people ${ }^{4)}$, and its utility is widely recognized ${ }^{5,6}$. The BBS has also been shown to be useful in assessing balance in patients with an acute stroke ${ }^{7}$, and there are reports on its relationship with maximum walking speed ${ }^{8)}$ and functional walking ability ${ }^{9}$. Because the BBS consists of test items taken from specific ADLs, and the SBT is thought to be related to balance performance, there is a high likelihood that a significant correlation will be seen between these two tests. The purpose of this study was to analyze the correlation between the results of the BBS and SBT among hemiplegic patients with stroke.

\section{SUBJECTS AND METHODS}

The subjects were 39 hemiplegic patients (25 men, 14 women; mean age, $69.4 \pm 11.0$ years) with stroke that had occurred within the preceding 6 months and who had good understanding of verbal instructions. They were all inpatients of the Research Institute for Brain and Blood Vessels-AKITA. Twenty-two patients had strokes due to cerebral infarction, and 17 patients had strokes due to intracerebral hemorrhage. Paralysis was on the left side in 21 patients and on the right side in 18 patients. The Brunnstrom recovery stage ${ }^{10)}$ for the legs was III in seven patients, IV 
1044 J. Phys. Ther. Sci. Vol. 25, No. 8, 2013

Table 1. The SBT judgment criteria

\begin{tabular}{ll}
\hline Grade 1 & Posture cannot be held and full assistance is needed \\
Grade 2 & Inadequate static balance ability in the center of the base of support \\
Grade 3 & Good static balance ability in the center of the base of support \\
Grade 4 & Good static balance ability near the limit of lateral stability at the base of support \\
\hline
\end{tabular}

in five patients, $\mathrm{V}$ in six patients, and VI in 21 patients. The study was conducted in accordance with the Declaration of Helsinki and its amendments. All subjects provided written informed consent before participating in this study. Patients diagnosed with lesions in the medulla oblongata or cerebellum and those diagnosed with dementia were excluded from the present survey.

The $\mathrm{SBT}^{2,3)}$ consists of five posture-holding tasks (sitting, stride standing, close standing, one-foot standing on the unparalyzed leg, and one-foot standing on the paralyzed leg). Four grades, 1-4, are used to judge the ability of patients to hold these postures (Table 1). The grade at which a subject is rated on a task is taken as the score for that task. Hence, the minimum SBT score is 5 , and the maximum is 20. Measurements start with sitting, and then proceed to stride standing, close standing, one-foot standing on the unparalyzed leg, and one-foot standing on the paralyzed leg, respectively. It is first determined whether the patient can maintain the center position of the COG. In other words, a judgment is made about the individual's static balance, which enables him or her to hold the projection point of the COG to the floor at the center of the base of support. If this task is not performed adequately, the grade is Grade 1 (1 point) or Grade 2 ( 2 points). If it is determined that this task is performed adequately, the examiners move on to judging the individual's ability to maintain the lateral position of the COG. In the lateral position of the COG, the static balance ability that enables the individual to hold the projection point of the COG to the floor near the limit of lateral stability is determined. If this task is not adequately performed, the judgment is Grade 3 ( 3 points). If this task is judged to be adequately performed, the judgment is Grade 4 (4 points). Measurements are made for the five postures with similar procedures (Appendices). Static balance is defined in the SBT as "steadily maintaining a COG without changing the base of support." In the BBS ${ }^{4}$, 14 tasks are judged on a 5-point scale from 0 to 4 , and the total score (BBS score) is taken to represent overall balance ability. Scores range from 0 to 56, with higher scores indicating better balance. The SBT and BBS were implemented on a single day in random order. The tests were given by 12 physical therapists. The examiners had full knowledge of the content of each test before performing the measurements.

Spearman's rank correlation coefficient was used in analyzing the relationship between BBS score and SBT score. The significance level was $<5 \%$. SPSS $16.0 \mathrm{~J}$ for Windows was used in the analysis.

\section{RESULTS}

The correlation coefficient for the BBS score and SBT score was $0.87(\mathrm{p}<0.01)$. Thus, a strong correlation was seen between the BBS and SBT.

\section{DISCUSSION}

In this study, the SBT showed high validity as a balance assessment index, and an analysis of the relationship between the BBS used in many studies and the SBT proposed by the authors was conducted. The results showed a strong positive correlation between the BBS score and SBT score. The reason behind this finding may be the influence of assessing static balance ability near the limit of stability, which is adopted as a judgment criterion in the SBT. In the SBT, the ability to maintain static balance in the center position of the COG is set as Grade 3, and the ability to hold a newly lateral position of the COG (posture in which the projection point of the COG on the floor is at a location near the limit of lateral stability at the base of support) is set as Grade 4. The measurement range is expanded further toward the side by changing the position in the same posture. The lateral position of the COG is a maintenance task in which joint torque related to joint immobilization is increased and the movement range of the center of pressure is narrowed ${ }^{11)}$. The level of difficulty may be imagined to be much higher than the center position of the COG. Thus, it would seem likely that the SBT, which includes judgment of the lateral position of the COG, is linked by a strong correlation with the BBS because it can make more detailed measurements of static balance ability due to left-right asymmetrical motor function in hemiplegic patients with stroke.

The BBS has been shown to be highly correlated with the Functional Reach Test $(\mathrm{r}=0.78)^{12}$ and Fugl-Meyer Assessment $(\mathrm{r}=0.71)^{13)}$, two widely used balance assessment indexes in patients with stroke. In the present study, the correlation coefficient of the BBS and SBT showed a similar high value when compared with those indexes. Interestingly, even among the present subjects who obtained the maximum score of 56 on the BBS, further differences in balance ability could be detected using the SBT. The SBT is done with only five posture-holding tasks and is characterized by simplicity and a short measurement time. Moreover, because there are no dynamic elements in the SBT, the risk of falls during measurement is small. The SBT is thought to be an assessment index that can predict overall balance ability with only a small burden on patients.

The results of this study were for hemiplegic patients with stroke who had unilateral functional impairment less than 6 months after the occurrence of stroke and cannot be applied to other diseases or disease stages. Further study with a greater range of patients is needed. 


\section{REFERENCES}

1) Murray MP, Seireg AA, Sepic SB: Normal postural stability and steadiness: quantitative assessment. J Bone Joint Surg, 1975, 57: 510-516. [Medline]

2) Suzuki M, Murakami K, Sakaki N, et al.: Development of a method for assessing the balance performance of hemiplegic patients -Part 1: The validity and reliability of the assessment method-. Rigakuryoho Kagaku, 2010, 25: 607-613 (in Japanese). [CrossRef]

3) Suzuki M, Murakami K, Sakaki N, et al.: Development of a method for assessing balance performance of hemiplegic patients -Part 2: Relationship between static balance test and balance performance-. Rigakuryoho Kagaku, 2010, 25: 873-880 (in Japanese). [CrossRef]

4) Berg K, Wood-Dauphinée S, Williams JI, et al.: Measuring balance in the elderly: preliminary development of an instrument. Physiother Can, 1989, 41: 304-311. [CrossRef]

5) Thorbahn L, Newton R: Use of the Berg balance test to predict falls in elderly persons. Phys Ther, 1996, 76: 567-583.

6) Shumway-Cook A: Predicting the probability for falls in communitydwelling older adults. Phys Ther, 1997, 77: 812-819. [Medline]
7) Berg K, Wood-Dauphinee S, Williams JI: The Balance Scale: reliability assessment with elderly residents and patients with an acute stroke. Scand J Rehabil Med, 1995, 27: 27-36. [Medline]

8) Harris JE, Eng JJ, Marigold DS, et al.: Relationship of balance and mobility to fall incidence in people with chronic stroke. Phys Ther, 2005, 85: 150-158. [Medline]

9) Usuda S, Araya K, Umehara K, et al.: Construct validity of functional balance scale in stroke inpatients. J Phys Ther Sci, 1998, 10: 53-56. [CrossRef]

10) Brunnstrom S: Motor testing procedures in hemiplegia: based on sequential recovery stages. Phys Ther, 1966, 46: 357-375. [Medline]

11) Fujisawa $\mathrm{H}$, Arisue I, Yanagawa $K$, et al.: A study of postural optimization during functional reach -Examination using a geometric model-. Rigaku Ryoho J, 2008, 35: 96-103 (in Japanese)

12) Smith PS, Hembree JA, Thompson ME: Berg Balance Scale and functional reach: determining the best clinical tool for individuals post acute stroke. Clin Rehabil, 2004, 18: 811-818. [Medline] [CrossRef]

13) Chou CY, Chien CW, Hsueh IP, et al.: Developing a short form of the Berg Balance Scale for people with stroke. Phys Ther, 2006, 86: 195-204. [Medline]

\section{Appendices}

\section{Criteria for sitting}

Explanation and posture conditions
"Please hold this posture for 10 seconds".
Center position of the COG

The subject's line of sight is forward, and the arms are held in front of the chest. The subject sits with the hip and knee joints in $90^{\circ}$ flexed positions, and the legs closed so that the inner thighs touch (the feet are not grounded on the floor). If this is difficult, the subject adopts a posture within the range that is possible. Measurements are done in bare feet.

Lateral positions of the COG
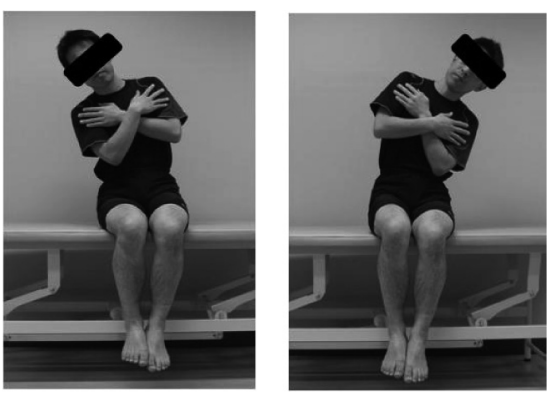

The trunk is bent slightly laterally from the center position of the COG, adopting a sitting position in which a vertical line descending from the mental protuberance to the floor is located approximately at the lateral side of the base of support.

Note:

The examiner confirms that the subject is not hooking the descending lower legs against the bed. 
1046 J. Phys. Ther. Sci. Vol. 25, No. 8, 2013

II. Criteria for stride standing

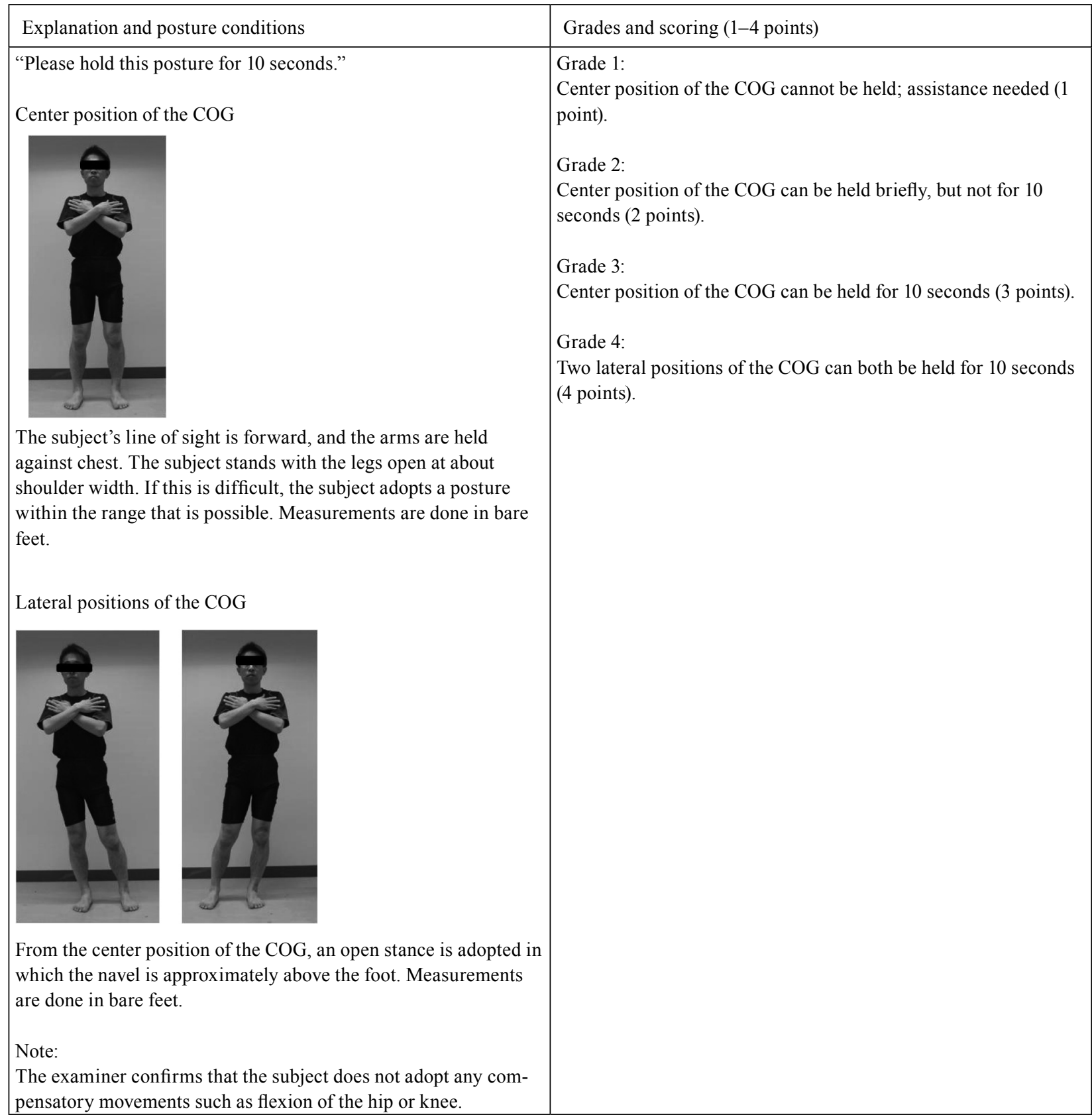


III. Criteria for close standing

\begin{tabular}{|c|c|}
\hline Explanation and posture conditions & Grades and scoring (1-4 points) \\
\hline $\begin{array}{l}\text { The trunk is bent slightly laterally from the center position of the } \\
\text { COG, adopting a close standing position in which a vertical line } \\
\text { descending from the mental protuberance to the floor is located } \\
\text { approximately at the lateral side of the base of support. } \\
\text { Note: } \\
\text { The examiner confirms that the subject does not adopt any com- } \\
\text { pensatory movements, such as flexion of the hip or knee, and does } \\
\text { not shift the hips laterally in the direction opposite to that of the } \\
\text { trunk lateral flexion. }\end{array}$ & $\begin{array}{l}\text { Grade 1: } \\
\text { Center position of the COG cannot be held; assistance needed ( } 1 \\
\text { point). } \\
\text { Grade 2: } \\
\text { Center position of the COG can be held briefly, but not for } 10 \\
\text { seconds ( } 2 \text { points). } \\
\text { Grade } 3 \text { : } \\
\text { Center position of the COG can be held for } 10 \text { seconds ( } 3 \text { points). } \\
\text { Grade } 4 \text { : } \\
\text { Two lateral positions of the COG can both be held for } 10 \text { seconds } \\
\text { (4 points). }\end{array}$ \\
\hline
\end{tabular}


1048 J. Phys. Ther. Sci. Vol. 25, No. 8, 2013

IV. Criteria for one-foot standing on the unparalyzed leg

\begin{tabular}{|c|c|}
\hline Explanation and posture conditions & Grades and scoring (1-4 points) \\
\hline $\begin{array}{l}\text { The trunk is bent slightly laterally from the center position of the } \\
\text { COG, adopting a one-foot standing position on the unparalyzed } \\
\text { leg in which a vertical line descending from the mental protuber- } \\
\text { ance to the floor is located approximately at the lateral side of the } \\
\text { base of support. } \\
\text { Note: } \\
\text { The examiner confirms that the subject does not adopt any com- } \\
\text { pensatory movements, such as flexion of the hip or knee, or shift } \\
\text { the pelvis laterally in the direction opposite to that of the trunk } \\
\text { lateral flexion. }\end{array}$ & $\begin{array}{l}\text { Grade 1: } \\
\text { Center position of the COG for one-foot standing on the unpara- } \\
\text { lyzed leg cannot be held; assistance needed (1 point). } \\
\text { Grade 2: } \\
\text { Center position of the COG for one-foot standing on the unpara- } \\
\text { lyzed leg can be held briefly, but not for } 10 \text { seconds ( } 2 \text { points). } \\
\text { Grade 3: } \\
\text { Center position of the COG for one-foot standing on the unpara- } \\
\text { lyzed leg can be held for } 10 \text { seconds ( } 3 \text { points). } \\
\text { Grade } 4 \text { : } \\
\text { Lateral position of the COG for one-foot standing on the unpara- } \\
\text { lyzed leg can be held for } 10 \text { seconds ( } 4 \text { points). }\end{array}$ \\
\hline
\end{tabular}


V. Criteria for one-foot standing on the paralyzed leg

\begin{tabular}{|c|c|}
\hline Explanation and posture conditions & Grades and scoring ( $1-4$ points) \\
\hline $\begin{array}{l}\text { "Please hold this posture for } 10 \text { seconds." } \\
\text { Center position of the COG } \\
\text { The subject's line of sight is forward, and the arms are held } \\
\text { against chest. The subject stands on one leg so that a vertical } \\
\text { line descending from the mental protuberance to the floor passes } \\
\text { approximately through the center of the support foot. If this is } \\
\text { difficult, the subject adopts a posture within the range that is pos- } \\
\text { sible. Measurements are done in bare feet. } \\
\text { Lateral position of the COG } \\
\text { pote: } \\
\text { the pelvis laterally in the direction opposite to that of the trunk } \\
\text { lateral flexion. } \\
\text { The trunk is bent slightly laterally from the center position of the } \\
\text { in which a vertical line descending from the mental protuberance } \\
\text { to the floor is located approximately at the lateral side of the base } \\
\text { of support. }\end{array}$ & $\begin{array}{l}\text { Grade 1: } \\
\text { Center position of the COG for one-foot standing on the para- } \\
\text { lyzed leg cannot be held; assistance needed (1 point). } \\
\text { Grade } 2 \text { : } \\
\text { Center position of the COG for one-foot standing on the para- } \\
\text { lyzed leg can be held briefly, but not for } 10 \text { seconds ( } 2 \text { points). } \\
\text { Grade } 3 \text { : } \\
\text { Center position of the COG for one-foot standing on the para- } \\
\text { lyzed leg can be held for } 10 \text { seconds ( } 3 \text { points). } \\
\text { Grade } 4 \text { : } \\
\text { Lateral position of the COG for one-foot standing on the para- } \\
\text { lyzed leg can be held for } 10 \text { seconds ( } 4 \text { points). }\end{array}$ \\
\hline
\end{tabular}

